\title{
PENGEMBANGAN MEDIA PEMBELAJARAN JARINGAN \\ KOMPUTER MENGGUNAKAN SOFTWARE MULTIMEDIA ADOBE FLASH CS6
}

\author{
Zulkifli $^{1}$ \\ Program Studi Informatika \\ Sekolah Tinggi Teknologi Payakumbuh \\ Email : zulkifli_pyk@yahoo.com
}

\begin{abstract}
Abstrak: Lembaga Pendidikan merupakan tempat mempersiapkan mahasiswa dalam bidang akademik, dan juga memiliki keterampilan yang tepat bagaimana belajar, beradaptasi dan berinovasi sehingga pembelajaran berbasis multimedia memiliki peran yang sangat signifikan untuk menciptakan keterampilan mahasiswa dalam matakuliah jaringan komputer dan dengan media

pemebelajaran ini mahasiswa dapat mengulang pelajarannya secara mandiri tanpa dibatasi tempat dan waktu. Penelitian ini merupakan penelitian pengembangan yang menggunakan model prosedural yang

terdiri dari 4 tahapan yaitu: (1) analisis Kebutuhan media pembelajaran, (2) Perancangan media pembelajaran, (3) Pembuatan media pembelajaran dan (4) Evaluasi serta validasi media

pembelajaran. Sehingga hasil akhir dari media pembelajaran jaringan komputer ini dapat dijalankan dengan hasil pengujian materi-materi pada halaman media pembelajaran didapatkan hasil baik dari hasil evaluasi akhir media pembelajaran jaringan komputer.
\end{abstract}

Kata kunci: Keterampilan, Multimedia, Media, Model, Evaluasi

Abstract: The Educational Institution is a place to prepare students in the academic field, and also have the right skills on how to learn, adapt and innovate so that multimedia-based learning has a very significant role to create student skills in Computer networking courses and with this learning media students can repeat their lessons independently without being limited by time and place. This research is a development research that uses a procedural model consisting of 4 stages, namely: (1) analysis of learning media needs, (2) design of learning media, (3) making learning media and (4) evaluation and validation of learning media. So that the end result of this computer network learning media can be run with the results of testing the material on the learning media page obtained good results from the results of the final evaluation of computer network learning media.

Keywords: Skills, Multimedia, Media, Model, Evaluation 


\section{PENDAHULUAN}

Ketika dunia ini memasuki era milenial, transformasi di segala bidang semakin pesat sekali termasuk juga di dunia pendidikan, kebutuhan akan tersedianya program pengajaran berbasis komputer juga semakin meningkat. Oenardi Lawanto (2001: 44) juga berpendapat, kemajuan teknologi informasi memang membawa dampak positif bagi dunia pendidikan. Teknologi informasi khususnya teknologi komputer dan internet, baik dalam hal perangkat keras maupun lunaknya, memberikan banyak tawaran dan pilihan bagi dunia pendidikan untuk menunjang proses pembelajaran peserta didik.

Lembaga pendidikan dituntut untuk mampu mempersiapkan siswa bukan dalam bidang akademik semata tetapi harus memiliki keterampilan yang tepat untuk bagaiman belajar, beradaptasi, dan berinovasi. Keterampilan yang dibutuhkan untuk sukses dalam kehidupan riil antara lain, kreatifitas dan kewirausahaan, literasi teknologi dan media, komunikasi efektif, pemecahan masalah, berfikir kritis dan berkerjasama (Listyowulan, 2013).

Untuk menciptakan siswa seperti itu, pembelajaran yang berbasis multimedia memiliki peran yang sangat signifikan yang akan menciptakan pembelajaran yang menyenangkan, kreatif dan kritis. Menurut Sadiman, dkk (2003: 19) penggunaan multimedia pembelajaran memperjelas penyajian pesan agar tidak terlalu bersifat visual, mengatasi keterbatasan ruang, waktu dan daya indra.

Salah satu platform yang dapat dimanfaatkan untuk membuat suatu media pembelajaran berbasis multimedia interaktif adalah Adobe Flash Profesional CS6 yang merupakan gabungan konsep pembelajaran dengan teknologi audiovisual yang mampu menghasilkan fitur-fitur baru yang dapat dimanfaatkan dalam pembelajaran. Fitur - fitur yang ada dalam Adobe Flash Profesional CS6 mampu mendesain animasi-animasi yang lebih menarik, tidak monoton dan memudahkan penyampaian materi.

\section{METODE PENELITIAN}

Penelitian ini menggunakan desain penelitian pengembangan. Adapun model pengembangan penelitian ini adalah model prosedural yang mengadaptasi model Borg dan Gall (1983:775). Metode penelitian ini meliputi empat tahap, yaitu (1) tahap analisis kebutuhan , (2) tahap Desain dan Perancagan media pembelajaran, (3)

membuat software mulitmedia pembelejaran, dan (4) tahap validasi dan revisi. Yang mana tahapan-tahapan tersebut dapat dilihat pada gambar 1 berikut:

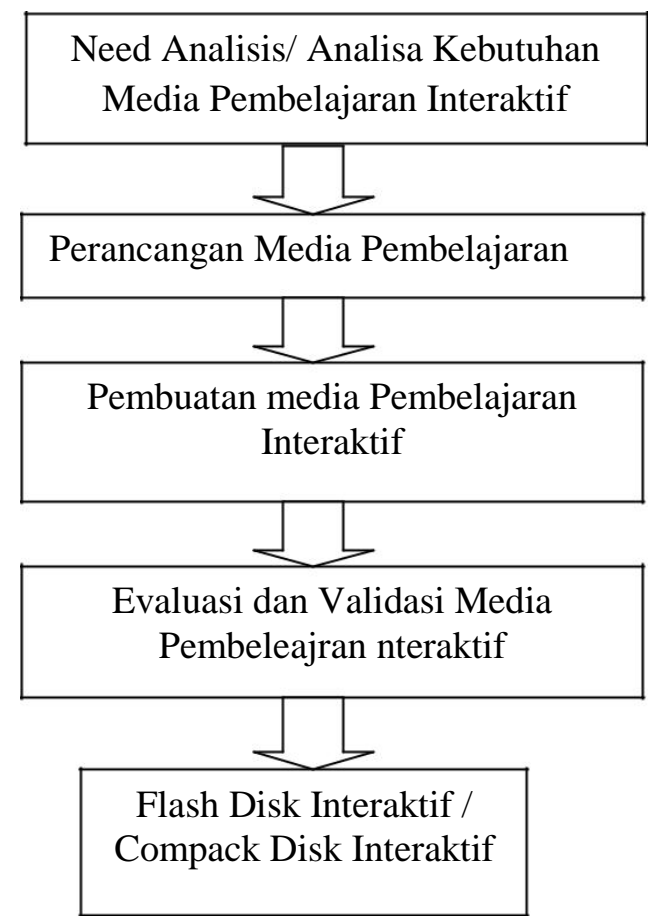

Gambar 1. Tahapan Penelitian

Kegiatan yang dilakukan pada tahap analisis kebutuhan adalah melakukan analisis kebutuhan pembelajaran, menulis standar kompetensi mata pelajaran, melakukan analisis pembelajaran, mengidentifikasi karakteristik dan perilaku awal peserta didik. Kemudian kegiatan selanjutnya adalah melakukan desain media Pembelajaran yang terdapat beberapa langkah dimulai dari 
menetapkan kompetensi standar, menetapkan dasar kompetensi, kemudian menganalisis pembelajaran, menentukan indikator-indikator, pengembangan alat

evaluasi pengumpulan data, pengembangan instructional materials, Merancang kegiatan pembelajaran yang harus dikerjakan dosen serta melakukan perancangan evaluasi media pembelajaran.

Kemudian pada tahap ketiga adalah melakukan persiapan pembuatan media pembelajaran yang dimulai dari menyiapkan materi yang dibutuhkan, seperti suara, film,tulisan dan gambar, kemudian membuat logika sistem dan kemudian membuat storyboard, membuat software media pembelajaran dan menyimpan media pembelajaran ke flashdish atau ke compack Disk

Dan pada tahap berikutnya pada tahap keempat dilakukan ujicoba dan revisi produk yang terdiri dari beberapa kegiatan dimulai dari validasi ahli media dan ahli materi, revisi produk, uji coba media pembelajaran yang terdiri dari uji coba perorangan, kelompok kecil dan revisi akhir media pembelajaran.

\section{HASIL DAN PEMBAHASAN}

\section{Desain awal Media Pembelajaran}

Desain awal media pembelajran ini dapat dilihat pada gambar 2 yang merupakan layout awal yang akan dikembangkan menjadi media pembelejaran interktif pada matakuliah jaringkan komputer di Sekolah Tinggi Teknologi Payakumbuh.

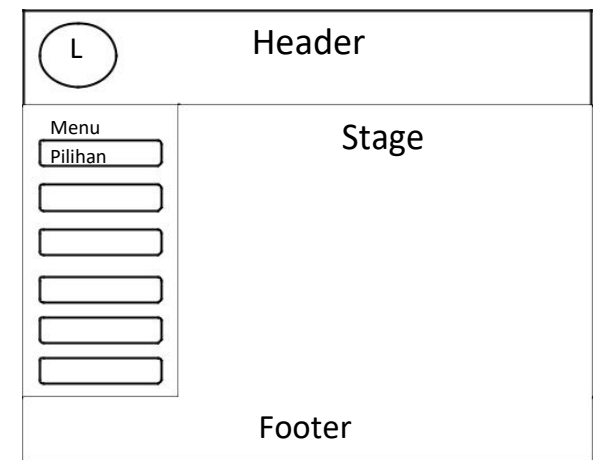

Gambar 2. Desain Awal Media Pembelajaran
Dari gambar 2 dapat dilihat layout awal desain pembelajaran jaringan komputer menggunakan multimedia yang terdiri dari beberapa bagian layout mulai dai bagian header, menu, stage dan footer.

Setelah layout desain pembelajaran selesai di tentukan selanjutnya adalah meembuat software media pembelajan jaringan komputer berdasarkan data yang didapat sebelumnya dengan menggunakan multimedia adobe flash Profesionla cs6 yang mana media pembelajaran jaringan komputer ini terdiri atas beberapa bagian yang bertujuan agar siswa dapat belajar secara mandiri, bagian-bagian dari produk media pemebelajaran ini adalah: 1) Logo,

2) judul Header, 3) desain header, 4) Stage, 5) image untuk baground stage, 6) footer, 7) menu pilihan materi pembelajaran jaringan komputer, dari 7 item komponen penyusun media pemebelajaran ini kemudian digabung melalui software adobe flash profesional cs6 dan kemudian disimpan pada media penyimpanan sehingga menghasilkan media pembelajaran yang interaktif dapat dilihat pada gambar 3 berikut:

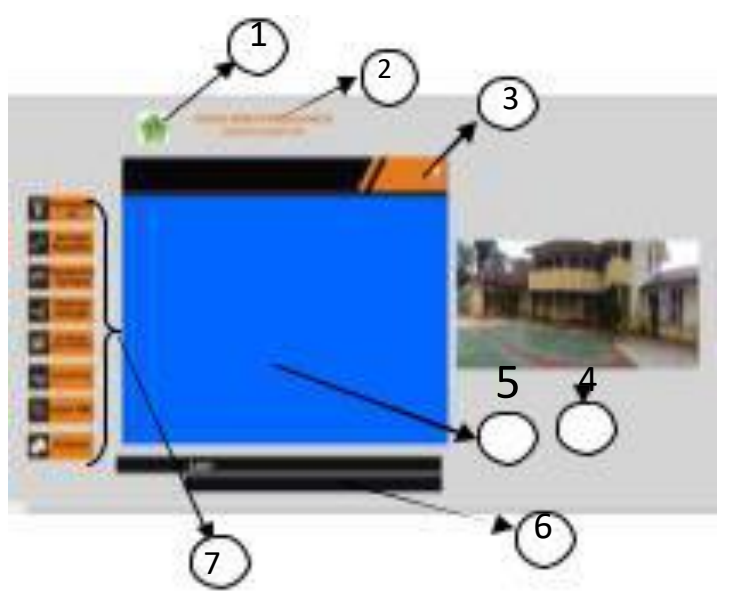

Gambar 3 susunan dan Perancangan media pembelajaran 


\section{Analisa Teknik}

Setelah selesai dilakukan desain media pembelajaran jaringan komputer tersebut langkah selanjutnya adalah mensimulasi hasil dari media pembelajaran yang telah dibuat menggunakan software adobe flash profesional cs6 seperti yang terdapat pada gambar 4, 5, 6, 7, dan gambar 8

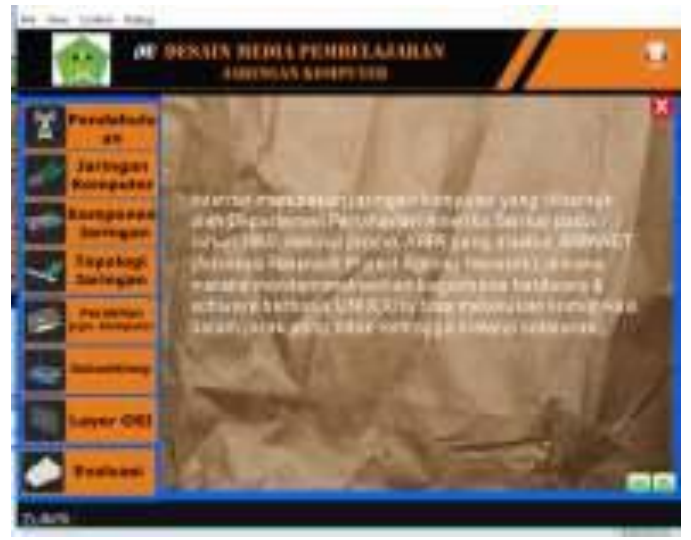

Gambar 4 Desain Pendahuluan materi

Pada bagian ini jika media pemebelajaran sudah dijalankan melalui media interaktif lalu dipilih menu pendahuluan maka akan menampilkan informasi tentang sejarah jaringan komputer dapat dilihat pada gambar 4

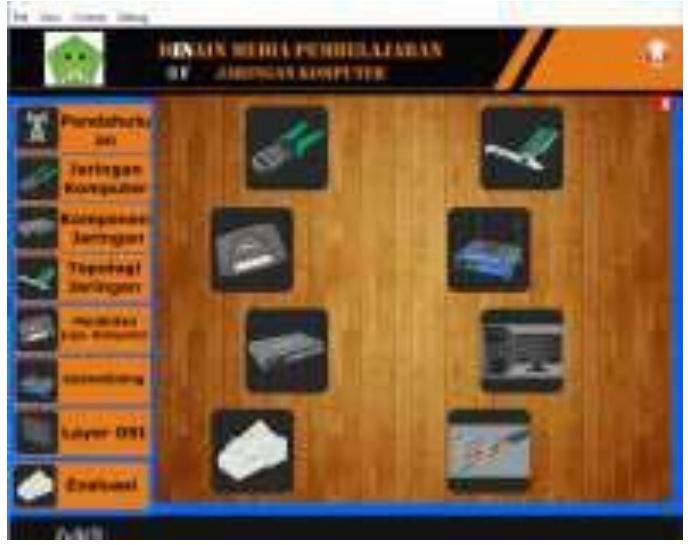

Gambar 5 Desain Komponen Jaringan

Pada bagian menu Komponen Jaringan Komputer media pembelajaran akan menampilan informasi peralatan atau komponen komponen yang dibutuhkan untuk merancang sebuah jaringan
Komputer seperti yaang dapat dilihat pada gambar 5.

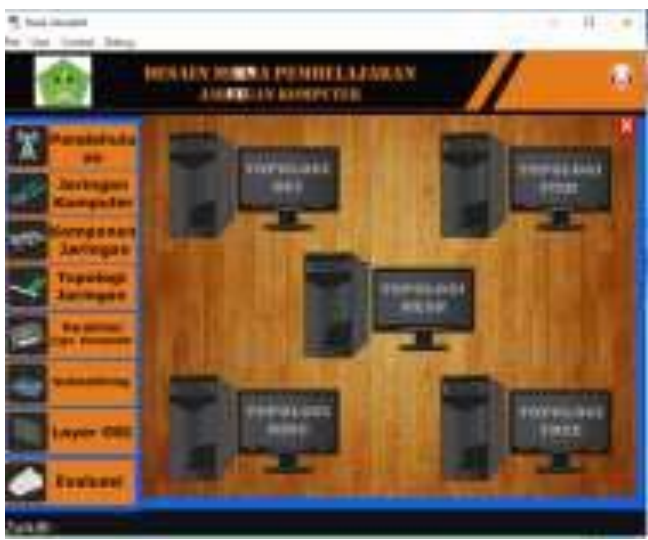

Gambar 6 Desain Topologi jaringan

Pada bagian menu Topologi jaringan media pembelajaran jika menu ini dipilih maka akan menampilkan informasi topologi jaringan mulai dari topologi bus, topologi star, topologi mesh, topologi ring dan topologi tree yang dapat dilihat pada gambar 6.

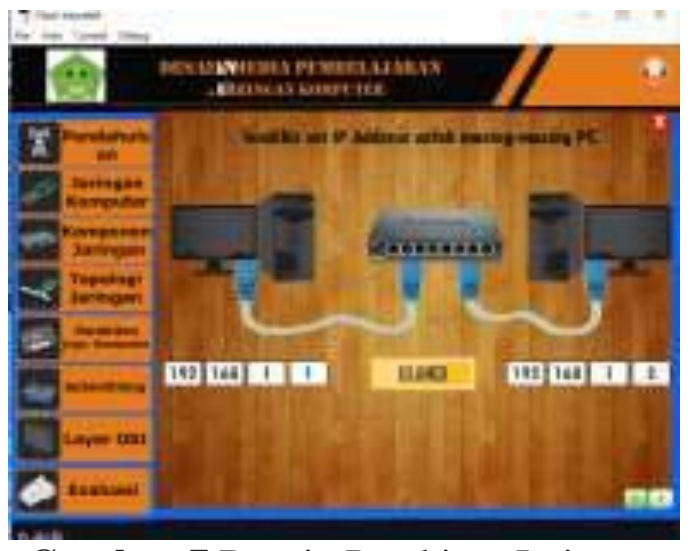

Gambar 7 Desain Perakitan Jaringan

Pada menu perakitan jaringan komputer, jika menu ini yang dipilih maka akan menampilkan tuturial cara membuat atau menghubungkan antara satu komputer ke komputer yang lain sehingga komputer yang terhubung dapat berkomunikasi, seperti yang dapat dilihat pada gambar 7 


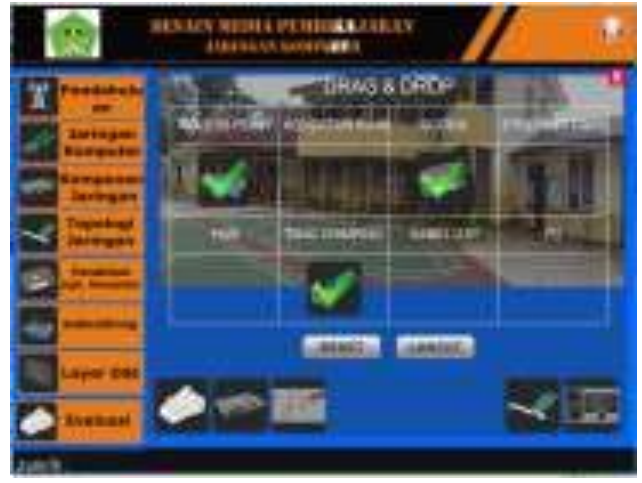

Gambar 8 Desain Evaluasi

Setelah siswa belajar melalui media pembelajaran jaringan komputer interktif ini, kemudian siswa juga bisa dievalausi melalui tombol menu evaluasi yang terdiri atas 20 pertanyaan evaluasi yang mana bobot nilai dari masing masing soal evaluasi adalah 5 poin seperti yang dapat dilihat pada gambar 8 .

\section{Uji Coba Produk Media Pembelajaran}

Dalam pengembangan produk media pembelajaran, media pembelajaran yang dikembangkan melalui proses validasi oleh ahli materi,validasi oleh media serta uji coba perorangan dan uji coba kelompok kecil uji coba kelompok kecil. Valiasi oleh ahli dan uji coba dilakukan dengan maksud agar produk media pembelajran yang dikembangkan layak digunakan. Data yang diperoleh kemudian dianalisis dan digunakan untuk memperbaiki atau meyempurnakan media pembelajaran yang dikembangkan. Dengan proses uji coba media pembelajaran seperti ini, diharapkan kualitas media yang dikembangkan menjadi lebih baik. Uji coba media pembelajaran dalam penelitian meliputi:

1. Validasi Ahli materi dan Ahli Media

Media pembelajaran yang dikembangkan divalidasi oleh satu orang ahli materi dan satu orang ahli multimedia yang terdiri dari aspek materi dan aspek tampilan. Hal ini dilakukan untuk mendapatkan input atau masukan guna penyempurnaan

media pembelajaran yang dikembangkan dan untuk mendapatkan kelayakan media pembelajaran layak untuk diuji cabakan kepada mahasiswa.

\section{Uji Coba Perorangan.}

Setelah mendapatkan validasi maka tahap berikutnya adalah dilakukan uji coba perorangan yang bertujuan untuk memperoleh bukti empirik tentang kelayakan media pembelajaran awal secara terbatas. Dalam uji coba perorangan penekanannya kepada faktor proses pembelajaran dari pada hasil belajar. Semua data yang diperoleh pada tahap ini yaitu: penilaian, komentar dan saran mahasiswa di susun dan dianalisis untuk revisi media pembelajaran sebelum uji coba kelompok kecil

\section{Uji Coba Kelompok Kecil}

Pada uji cobs kelompok kecil ini diperlukan untuk mengumpulkan informasi untuk melakukan revisi dan perbaikan media pembelajaran selanjutnya. Semua data informasi yang didapt pada tahap ini seperti komentar, penilaian serta saran dilakukan analisis untuk merevisi dan memperbaiki media pembelajaran yang dikembangkan. Dari hasil ujicoba, media pembelajaran jaringan komputer interaktif diperbaiki dan disempurnakan menjadi media pembelajaran akhir atau final dan selanjutnya media pembelajaran jaringan komputer tersebut dapat diimplementasikan.

\section{Desain Akhir}

Setelah dilakukan desain dan perancangan produk media pembelajaran jaringan komputer yang bersifat interaktif dan kemudian dilanjutkan dengan simulasi program maka didapatlah hasil akhir dari produk media pembelajaran jaringan Komputer secara interaktif seperti terlihat pada gambar 9. 


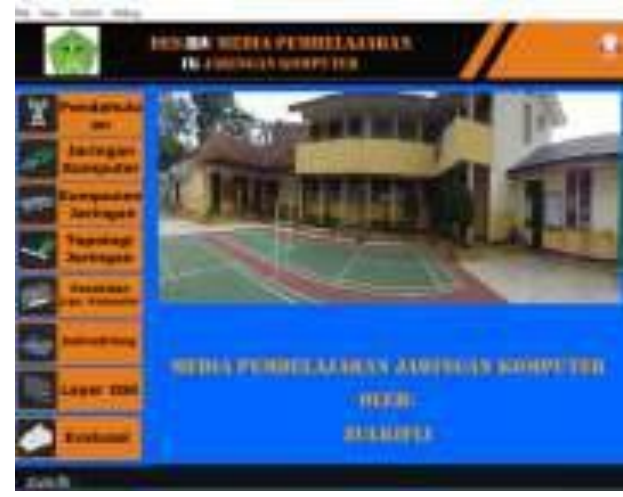

Gambar 9 Desain Akhir Produk Media Pemebelajaran

Setelah Produk Akhir media pembelajaran jaringan komputer didapat maka selanjutnya dilakukan pengujian sistem. Pengujian dijalankan pada semua materi pada halaman-halaman dari media pembelajaran yang dirancang untuk memastikan materi-materi perkuliahan pada bagian-bagian halaman dapat dipelajari dan beroperasi secara interaktif dan siswa lebih mudah memahami materi jaringan komputer tersebut, lebih jelasnya ditampilkan hasil pengujian pada tabel 1 .

Tabel 1. Hasil Pengujian Media Pembelajaran

\begin{tabular}{llcc}
\hline No & \multicolumn{1}{c}{ Kriteria } & Nilai & Hasil \\
\hline 1 & $\begin{array}{l}\text { Kesesuaian urutan } \\
\text { materi }\end{array}$ & 5 & $\begin{array}{l}\text { Sangat } \\
\text { Baik }\end{array}$ \\
\hline 2 & $\begin{array}{l}\text { Ketepatan materi } \\
\text { dengan silabus }\end{array}$ & 4 & Baik \\
\hline 3 & $\begin{array}{l}\text { Kemudahan } \\
\text { memahami materi }\end{array}$ & 4 & Baik \\
\hline 4 & $\begin{array}{l}\text { Kesesuaian } \\
\text { evaluasi dengan } \\
\text { materi }\end{array}$ & 4 & Baik \\
\hline 5 & $\begin{array}{l}\text { Kesesuain Contoh } \\
\text { dengan materi }\end{array}$ & 4 & Baik \\
\hline 6 & $\begin{array}{l}\text { Kejelasan umpan } \\
\text { balik }\end{array}$ & 3 & Cukup \\
\hline 7 & $\begin{array}{l}\text { Kemudahan } \\
\text { Pengunaan } \\
\text { Program }\end{array}$ & Baik \\
\hline
\end{tabular}

\section{KESIMPULAN}

Dari uraian diatas maka dapat diambil kesimpulan sebagai berikut:

1. Dengan media pembelajaran jaringan komputer ini mahasiswa dapat belajar mandiri sehingga mahasiswa dapat belajar dirumah menggunakan media pembelajaran interaktif ini.

2. Bisa Meningkatkan pemahaman materi mahasiswa karena melalui media pembelajaran yang mudah dipahami mahasiswa dapat belajar berulan-ulang

3. Membantu Dosen menjelaskan hal-hal sulit karena melalui media pemebelajaran ini dapat mentutorialkan atau mensimulasikan jaringan komputer

4. Produk media pembelajaran dapat berupa $\mathrm{CD}$ atau meia Flash Disk untuk menjalankannya hanya butuh interface USB

\section{DAFTAR PUSTAKA}

Arsyad Azhar. 2005. Media Pembelajaran. Jakarta: PT.Raja Grafindo Persada.

Dick, Walter \& O, Carey, 2005, The Syistemathic Design of Instruction, Glenview, Illionis: Scott, Forestman\&Company

Gagne\&Briggs, 1979, Principle of Instructional Design (2 ed), New York: Holt Rinehart and Winston.

Lawanto, Oenardi, 2001, Pembelajaran Berbasis Web Sebagai Metoda Komplemen Kegiatan Pendidikan dan Pelatihan, Jurnal Unitas Vol. 9, No.1.

Mukminan, 2004, Desain Pembalajaran, Diktat Mata Kuliah Desain Pembelajaran Program Pascasarjana Program Studi TP.

Sadiman, Arif S. dkk., 2003, Media

Pendidikan: Pengertian, Pengembangan dan Pemanfaatannya, Jakarta: Pustekkom Diknas dan PT. Raja Grafindo Perkasa. 
Sudjana, Nana dan Ahmad Riva'i. 2003.

Tekhnologi Pengajaran. Jakarta:

Bumi Aksara

Suparman, M. Atwi, 2001, Desain Instruksional, Jakarta: PAU-PPAI, Universitas Terbuka.

Sutedjo, Budi Dharma Oetomo, 2002, EEducation: Konsep Teknologi dan Aplikasi Internet Pendidikan, Yogyakarta: Andi. 